Cold Spring Harb Perspect Med 6: a027094 (2016)

\title{
Corrigendum: Reengineering the Tumor Microenvironment to Alleviate Hypoxia and Overcome Cancer Heterogeneity
}

\author{
John D. Martin, Dai Fukumura, Dan G. Duda, Yves Boucher, and Rakesh K. Jain
}

In the first version of this article, the legend to Figure $3 \mathrm{~B}$ indicated that the images were from Chauhan et al. (2012) rather than from Chauhan et al. (2013). The authors apologize for this error. In the current version of the article, the legend has been amended to include the correct reference citation.

\section{REFERENCES}

Chauhan VP, Stylianopoulos T, Martin JD, Popovic Z, Chen O, Kamoun WS, Bawendi MG, Fukumura D, Jain RK. 2012. Normalization of tumour blood vessels improves the delivery of nanomedicines in a size-dependent manner. Nat Nanotechnol 7: 383-388.

Chauhan VP, Martin JD, Liu H, Lacorre DA, Jain SR, Kozin SV, Stylianopoulos T, Mousa AS, Han X, Adstamongkonkul P, et al. 2013. Angiotensin inhibition enhances drug delivery and potentiates chemotherapy by decompressing tumour blood vessels. Nat Commun 4: 2516.

Copyright (C) 2016 Cold Spring Harbor Laboratory Press; all rights reserved

Advanced Online Article. Cite this article as Cold Spring Harb Perspect Med doi: 10.1101/cshperspect.a031195 


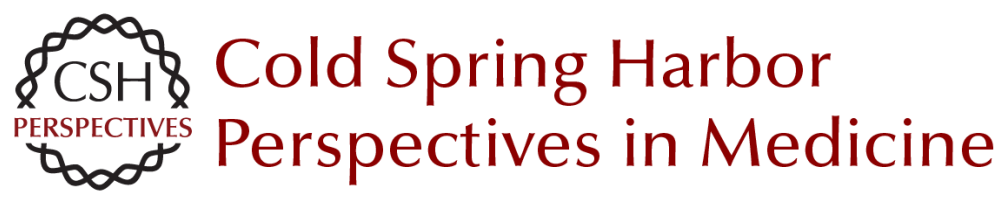

\section{Corrigendum: Reengineering the Tumor Microenvironment to Alleviate Hypoxia and Overcome Cancer Heterogeneity}

John D. Martin, Dai Fukumura, Dan G. Duda, Yves Boucher and Rakesh K. Jain

Cold Spring Harb Perspect Med 2016; doi: 10.1101/cshperspect.a031195

Subject Collection

For additional articles in this collection, see http://perspectivesinmedicine.cshlp.org/cgi/collection/ 